\title{
Miguel Ángel Ladero Quesada, Guzmán. La CASA DUCAL DE MEDINa SidONIa EN SEVILLA Y SU REINO.1282-1521. EDITORIAL DyKINSON, S.L., MADRID, 2015, 712 PÁGINAS. ISBN 9788490852743.
}

\author{
Manuel García Fernández \\ Universidad de Sevilla
}

No por esperado deja de sorprendernos gratamente el libro que hoy participamos. Hay síntesis históricas que, como esta, transcienden más allá del teórico discernimiento que adelanta su título y que justifican siempre las expectativas despertadas. Pues, en efecto, Guzmán. La casa ducal de Medina Sidonia en Sevilla y su reino.1282-1521 es mucho más que un magnífico estudio sobre este linaje nobiliario; el mas importante de Andalucía entre los siglos XIII al XV, señores de Sanlúcar de Barrameda, condes de Niebla, duques de Medina Sidonia, y su contexto social, económico y político en la ciudad de Sevilla y su antiguo reino. Porque inserto plenamente en la renovación metodológica de la llamada nueva historia nobiliaria, la prolija monografía del profesor Ladero Quesada abunda en una vasta investigación archivística, seria y minuciosa -como este brillante medievalista acostumbra a realizar- que no sólo diseña el objetivo histórico de las relaciones familiares y la acción política de los miembros del linaje Guzmán, sino que también despliega con maestría el análisis comparado de sus diferentes señoríos, las fuentes del poder y las rentas feudales. En fin, como él mismo señala, el autor pretende también "la reconstrucción del mundo de valores sociales y culturales que vivieron sus miembros y conoció el resto de la sociedad de aquellos siglos" bajomedievales.

Estamos, pues, ante una obra excepcional. Fruto de muchos años de investigación y conocimiento de los vastos fondos medievales del Archivo Ducal de Medina Sidonia -como fuente directa y primaria de la obra- pero también del Archivo General de Simancas, del Archivo Histórico Nacional (sección nobleza) y del Archivo Municipal de Sevilla, entre otros. Todo ello justifica y explica la densidad heurística del trabajo, la minuciosidad de sus notas complementarias, la maestría en la bibliografía utilizada y citada, etc. Sin olvidar lógicamente el impresionante anexo documental, que complementa los contenidos fundamentales de la obra. Trabajo, en fin, modélico y verdaderamente enciclopédico; pero al mismo tiempo de fácil y apasionante lectura, de exquisita pluma, al mejor estilo del profesor Ladero Quesada. Riesgo cero. Un libro difícilmente 
superable como referencia metodológica para futuras investigaciones sobre la alta nobleza castellana bajo medieval. Imprescindible para los medievalistas interesados en el linaje de Guzmán y sus diferentes señoríos andaluces a finales de la Edad Media y en el tránsito a la Edad Moderna.

Se estructura el texto en su conjunto en torno a una metodología de análisis cronológica; pues siguiendo en muchos aspectos a don Pedro Barrantes Maldonado se organiza en torno a ocho densos capítulos - especialmente detallado el cuatro, que abarca toda la segunda mitad del siglo XV- que finalizan con un brillante epílogo a modo de resumen, además de los referidos anexos documentales y los obligados créditos de las siglas, las fuentes y la selecta bibliografía.

En el capítulo primero analiza el profesor Ladero Quesada la génesis señorial de los fundadores de la casa de Guzmán en Sevilla y su antiguo reino: la historia y la leyenda de Alonso Pérez de Guzmán, el "Bueno" (1282-1309) y su esposa María Alfonso Coronel (1282-1331) en el contexto de los avatares políticos y militares de finales del siglo XIII y comienzos de del siglo XIV. En el capítulo segundo se estudia la proyección social de los señores de Sanlúcar de Barrameda y su consolidación como la primera casa noble de Andalucía al servicio de la corona castellana en la frontera, así como su apoyo a la causa trastámara, ya en tiempos de Juan Alfonso Pérez de Guzmán, I conde Niebla (1365-1396). El autor inicia ahora una práctica expositiva fundamental que reitera en próximos capítulos; el análisis evolutivo de los diferentes señoríos de la casa de Guzmán: básicamente las villas de Sanlúcar de Barrameda, Medina Sidonia y Niebla. El capítulo tercero, uno de los más conseguidos en nuestra opinión, se centra en la figura épica y excepcional del "buen conde de Niebla" don Enrique de Guzmán (1396-1436) quien murió -como es bien sabido- ahogado en las playas de Gibraltar al intentar conquistar la plaza y salvar la vida de sus vasallos, como recoge el romancero tradicional castellano, para gloria del linaje. El capítulo cuarto es, sin lugar a dudas, el más extenso y complejo pues abarca toda la segunda mitad del siglo XV con el final de la guerra de Granada. Con notable maestría, el profesor Ladero Quesada demuestra el perfecto conocimiento de las disyuntivas sociales y políticas castellanas del enfrentamiento entre nobleza y monarquía. Lo que llevaría a la casa de Guzmán a la cúspide del poder en Andalucía, en los tiempos ya del I duque de Medina Sidonia, Juan de Guzmán (1436-1468), conquistador de Gibraltar en 1462, y sobre todo de su hijo Enrique de Guzmán (1468-1492) enfrentado casi siempre al marqués de Cádiz, Rodrigo Ponce de León, por el control de la ciudad de Sevilla y su reino en donde ambos tenían el núcleo de sus señoríos andaluces. Los capítulos quinto y séptimo constituyen una misma trama en la unidad analítica y temática sobre los señoríos, el patrimonio, las rentas señoriales y el poder feudal de la casa de Guzmán desde 1436 a finales del siglo XV y comienzos del siglo XVI, que, en nuestra opinión, integran una única y coherente dinámica, el estudio de la hacienda y la fiscalidad señorial. Desarrollo que, sin embargo, se interrumpe -según los criterios del autor-con la inclusión del capítulo sexto sobre el apogeo político y la crisis sucesoria de la casa ducal de Medina Sidonia en tiempos de Juan de Guzmán (1492-1507) y de su hijo Enrique de Guzmán 
(1507-1513). Pero ya hemos señalado la metodología cronológica de la exposición de la obra como hilo conductor de la historia de la casa de Guzmán. En el estudio de la hacienda señorial, de las rentas y la administración ducal despliega el profesor Ladero Quesada todos sus discernimientos como historiador de la fiscalidad bajo medieval. Se trata de uno de los apartados más conseguidos y brillantes del libro. En efecto, los diferentes señoríos -Sanlúcar de Barrameda, Medina Sidonia, Niebla, etc.- son objetos de un exhaustivo análisis comparado que integran diversos y variados aspectos administrativos, hacendísticos y socio-económicos, que se complementan, además, con un anexo de documentos y mapas para facilitar la compresión del texto. El capítulo octavo se dedica al "modo de vida noble" de la casa de Guzmán, como las redes sociales y feudales, la vida cotidiana, la cultura, el patrimonio, la memoria de los antepasados, y la religiosidad de los diferentes señores.

Para concluir estamos, pues, ante un libro extraordinario y pionero en su estilo que renueva profundamente con notables aportaciones los estudios sobre la nobleza y el régimen señorial en la corona de Castilla en los últimos siglos medievales desde la metodología de análisis de la llamada historia total. Un texto esperado, desde luego, pero que, como bien señala y justifica el profesor don Miguel Ángel Ladero Quesada en su presentación, "nunca fue mi voluntad dejar a medio hacer lo que había comenzado con entusiasmo durante mis visitas a Sanlúcar de Barrameda" en el Archivo General de la Fundación Casa Ducal de Medina Sidonia. La espera ha merecido la pena, pues estamos ante una obra cumbre de la investigación para la comprensión definitiva de la casa ducal de Medina Sidonia en Sevilla y su reino entre 1282-1521. 
